\title{
Tumor desmoplásico de pequenas células redondas: relato de um caso de uma neoplasia de difícil diagnóstico
}

\author{
Desmoplastic round small cell tumor: a case report of a neoplasm of difficult \\ diagnosis
}

\author{
Daniel Cury Ogata, ${ }^{1}$ Joel Takashi Totsugui, ${ }^{2}$ Tiago Noguchi Machuca, ${ }^{3}$ Sérgio Ossamu loshii, ${ }^{2}$ Alessandro Cury Ogata, ${ }^{4}$ \\ Léo Fernando da Silva Ditzel Filho'
}

\section{Resumo}

O tumor desmoplásico de pequenas células redondas (TDPCR) é uma neoplasia rara, que foi recentemente relatada por Gerald et al. Foram descritos aproximadamente 101 casos na literatura, tendo uma localização predominantemente intra-abdominal e acometendo com maior freqüência crianças e adultos jovens. Os autores relatam um caso de TDPCR em adulto jovem de 24 anos. Este paciente apresentava quadro inespecífico de náuseas, vômitos, além de único episódio de hematêmese. Ao exame físico constatou-se massa sólida em epigástrio e hipocôndrio esquerdo. Estudos de imagem confirmaram a existência de processo expansivo e também evidenciaram linfonodomegalia retroperitoneal. O diagnóstico foi firmado através de videolaparoscopia, obtendo material de biópsia. Devido a inespecificidade da amostra, optou-se pela utilização da imunoistoquímica. A análise deste estudo revelou que a neoplasia era positiva para marcadores epiteliais, mesenquimais e fracamente positiva para cromogranina, sendo que estes resultados favoreceram o diagnóstico de TDPCR. Devido à doença estar localmente avançada, o tratamento proposto foi quimioterapia com Ciclofosfamida e Paclitaxel. Contudo, o paciente apresentou resposta apenas parcial, recusando-se a utilizar outro tratamento de segunda linha. Atualmente encontra-se sob cuidados de apoio, com seguimento de 18 meses.

Palavras-chave: Tumor desmoplásico; Diagnóstico diferencial; Neoplasias abdominais; Imunohistoquímica; Adulto.

\section{Abstract}

Desmoplastic Small Round Cell Tumor (DSRCT) is a rare neoplasm of difficult diagnosis, recently described by Gerald et al. There are reports of nearly 101 cases in the literature, being the intra-abdominal region its most common location and children and young adults its preferred age group. This paper reports a case of DSRCT in a young adult of 24 years of age. This patient presented unspecific symptoms of nausea, vomiting and a single episode of hematemesis. Upon physical examination a solid mass on the epigastrium and left hypochondrium was found. Image diagnostic procedures confirmed the existence of the expansive process and also revealed enlarged retroperitoneal lymphonodes. Diagnosis was achieved through videolaparoscopic biopsy. Histologic sections stained with hematoxylin/eosin were inconclusive and immunohistochemical analysis was required to establish the diagnosis. This analysis revealed positivity to epithelial and mesenchimal markers and weak posivity to chromogranin A, characteristic results of DSRCT. Due to the fact that the disease was locally advanced, the patient was treated with chemotherapy (cyclofosfamide and paclytaxel). However, since there was only partial response to the treatment, the patient refused to undergo any second line option of therapy. Presently, the patient is being submitted only to supportive care, within an 18-month follow-up program.

Key words: Desmoplastic tumor; Differential diagnosis; Abdominal neoplasms; Immunohistochemistry; Adult.

\footnotetext{
${ }^{1}$ Doutorando de Medicina, Pontifícia Universidade Católica do Paraná

${ }^{2}$ Professor Adjunto de Anatomia Patológica, Pontifícia Universidade Católica do Paraná

${ }^{3}$ Doutorando de Medicina, Universidade Federal do Paraná

${ }^{4}$ Cirurgiāo Oncológico, Hospital Nossa Senhora das Graças, PR

Trabalho realizado no Laboratório de Patologia Experimental da PUC-PR Enderę̧o para correspondência: Daniel Cury Ogata, R. dos Dominicanos 1291, Boa Vista, CEP: 82560-390 Curitiba, PR. E-mail: daniel_ogata@medcenter.com
} 


\section{INTRODUÇÃO}

O tumor desmoplásico de pequenas células redondas (TDPCR) foi primeiramente descrito por Gerald et al. (1991), como uma entidade distinta na classificação de tumores de células pequenas e redondas. ${ }^{1}$ Existem aproximadamente 101 casos desta neoplasia relatados na literatura, apresentando maior incidência em crianças e adultos jovens, preferencialmente por adolescentes do sexo masculino, com média de idade de 21 anos. $^{2,3} \mathrm{~A}$ localização é quase que exclusivamente intra-abdominal. ${ }^{4}$ O diagnóstico é realizado através de imunoistoquímica, que se mostra positiva para marcadores epiteliais, mesenquimais e neurais, sendo que este padrão de diferenciação representa característica altamente sugestiva do TDPCR. As metástases ocorrem mais comumente em peritônio, fígado e tecido linfóide e a principal causa de óbito é o extenso acometimento intra-abdominal. ${ }^{3}$

O prognóstico é mau devido à inexistência de adequada padronização para o seu tratamento, além do fato destes tumores não apresentarem resposta significativa à quimioterapia e à radioterapia. ${ }^{4,5}$

\section{RELATO DE CASO}

Os autores relatam o caso de paciente masculino, 24 anos de idade, que procurou auxílio médico por náuseas, vômitos e episódio de hematêmese. No exame físico, palpava-se em hipocôndrio esquerdo, massa volumosa e indolor. Realizou-se endoscopia digestiva alta, que demonstrou deformidade da mucosa gástrica com focos de enantemas. $\mathrm{O}$ exame ultra-sonográfico do abdome demonstrou massa sólida com contornos lobulados e arquitetura heterogênea, localizada em epigástrio e hipocôndrio esquerdo, com compressão da parede posterior do estômago, anteriormente deslocada. A tomografia computadoriza confirmou os achados ecográficos. Contudo, mensurou o tumor em $15 \mathrm{~cm}$ no maior eixo e descreveu a localização como em hipocôndrio esquerdo, entre o baço e a grande curvatura gástrica. Não havia plano de clivagem entre estas estruturas. Também se evidenciou infiltração da cauda do pâncreas e linfonodomegalia retroperitoneal paraaórtica $(2 \times 3 \mathrm{~cm})$ (figura 1$)$. Durante a investigação, a videolaparoscopia evidenciou massa em hipocôndrio esquerdo, aderida à aorta e a veia cava inferior, infiltrando diretamente a parede gástrica. Devido à irressecabilidade do tumor, realizou-se apenas uma biópsia. $\mathrm{O}$ exame histopatológico revelou arquitetura homogênea, demonstrando agregados de células bem definidas com estroma fibrodesmoplásico. A complementação diagnóstica foi realizada através de exame de imunoistoquímica com a técnica de avidina- biotina peroxidase, que favoreceu o diagnóstico de TDPCR (Tabela 1, figuras 2 e 3).

Após o estabelecimento do diagnóstico, o paciente foi submetido à quimioterapia, com seis ciclos de Ciclofosfamida e Paclitaxel. A resposta foi parcial, havendo apenas redução de $20 \%$ da massa. O paciente se recusou a iniciar tratamento de segunda linha. Atualmente encontra-se sob cuidados de apoio e seguimento de 18 meses.

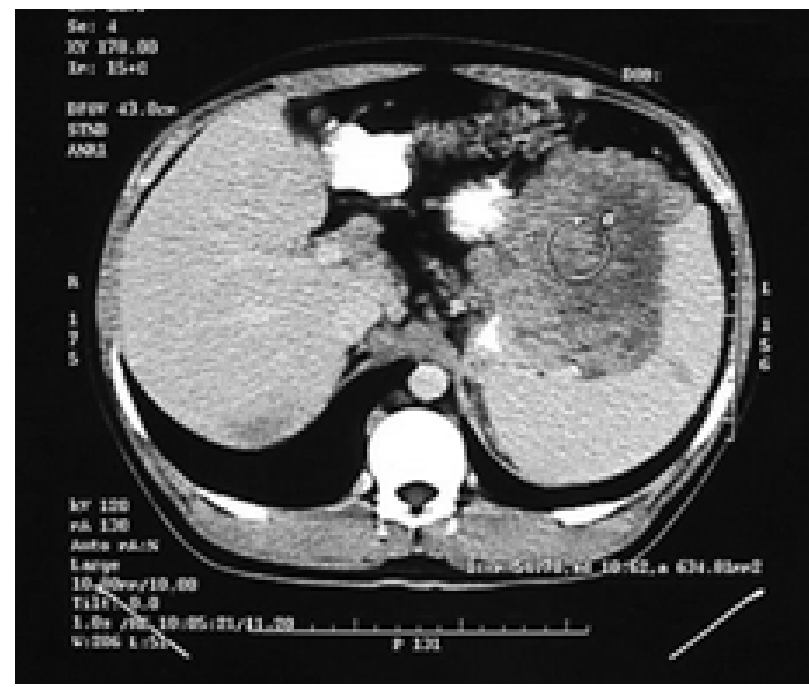

Figura 1. Tomografia axial computadorizada mostrando neoplasia entre grande curvatura gástrica e baço, não havendo plano de clivagem entre estas estruturas.

Tabela 1. Marcadores imunoistoquímicos avaliados na neoplasia

\begin{tabular}{c|c}
\hline ANTICORPO & RESULTADO \\
\hline Citoqueratina AE 1/AE3 & Positivo \\
\hline CAM 5.2 & Positivo \\
\hline Vimentina & Positivo \\
\hline Desmina & Positivo \\
\hline Cromogranina A & Fracamente Positivo \\
\hline CD99 & Negativo \\
\hline
\end{tabular}

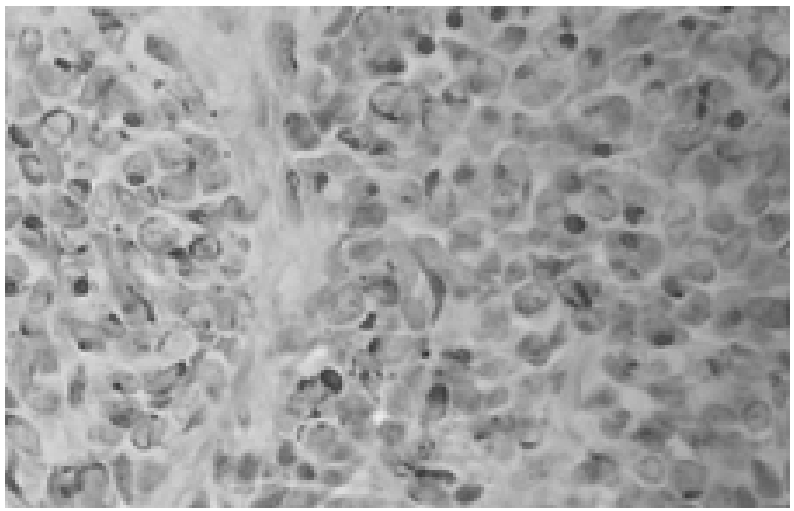

Figura 2. Positividade da neoplasia para desmina, padrão globóide "dotlike". 


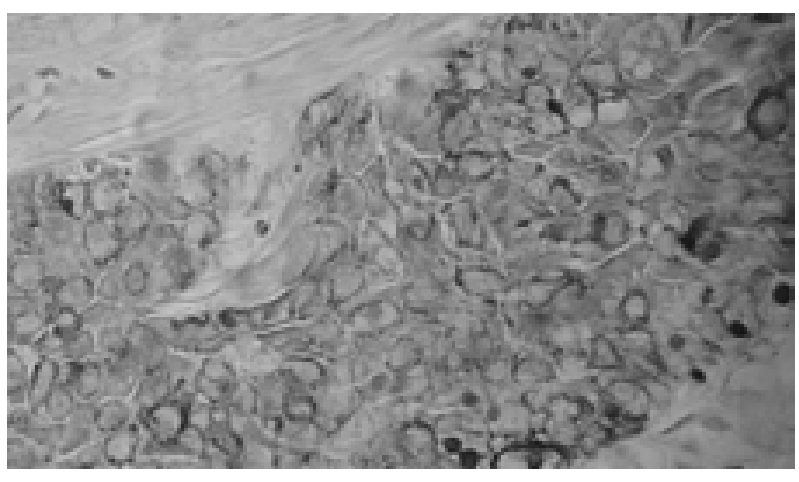

Figura 3. Positividade da neoplasia para citoqueratina AEl/AE3, padrão difuso citoplasmático.

\section{DISCUSSÃO}

Existem aproximadamente 101 casos de TDPCR relatados na literatura, incluindo séries de 19 casos descritos por Gerald et al., ${ }^{1}, 27$ casos adicionais relatados por Gerald e Rosai ${ }^{6}$ e 22 casos descritos por Ordonez et al. ${ }^{7}$

A média de idade dos 101 casos foi de 21 anos, com idades que variavam entre 6 e 48 anos, sendo que 78 pacientes eram masculinos e 23 femininos. ${ }^{3} \mathrm{O}$ padrão de acometimento abdominal geralmente é descrito como múltiplos nódulos aderidos à superfície peritoneal. Outra forma de apresentação foi de massa dominante, apresentando vários nódulos satélites menores preenchendo a cavidade peritoneal. Nesta situação o local primário pode não ser aparente. ${ }^{4}$ Os sintomas mais comuns são o desconforto geniturinário ou gastrintestinal, secundário às massas pélvicas e/ou abdominais. Raramente podem ocorrer sintomas como obstrução intestinal, massa escrotal, icterícia e impotência. ${ }^{1,3,6,7}$ Noventa e nove pacientes tinham o tumor na cavidade pélvica ou abdominal, geralmente próximo ao mesentério, com aderências freqüentes ou com múltiplas metástases no momento. ${ }^{3,4} \mathrm{~A}$ adenopatia retroperitoneal presente neste relato é infreqüente, sendo descrita em apenas 15 casos na literatura. ${ }^{1,3,6,7}$

A patogênese da diferenciação multi-imunofenotípica deste tumor permanece desconhecida. A translocação recíproca do cromossomo $\mathrm{t}(11 ; 22)(\mathrm{p} 13 ; \mathrm{q} 12)$ tem sido relatada e pode ser a pista para a descoberta de sua origem. Esta translocação é exclusiva do TDPCR, mas os pontos de quebra, acometem duas regióes cromossômicas, previamente implicadas no desenvolvimento de outras neoplasias malignas. A banda 22q12 é o local do sarcoma de Ewing (EWS) e a 11p13 é o do tumor de Wilms (WT1). ${ }^{8-12}$

A análise histopatológica do tumor mostra agregados celulares bem definidos com padrão de crescimento infiltrativo, permeados por estroma celular fibromixóide desmoplásico. Tipicamente, as células malignas são pequenas, com núcleo oval ou redondo e, ocasionalmente, com escasso citoplasma eosinofílico. ${ }^{4,10}$

O diagnóstico diferencial inclui uma variedade de neoplasias de pequenas células, como o rabdomiossarcoma alveolar, linfoma maligno, sarcoma de Ewing, nefroblastoma, neuroblastoma e tumores de células germinativas. ${ }^{13}$ Anteriormente ao advento da imunoistoquímica, o TDPCR freqüentemente causava muitas dúvidas diagnósticas, uma vez que devido à falta de achados histopatológicos específicos, sua diferenciação com outros tumores de pequenas células era difícil. ${ }^{4}$

O perfil imunoistoquímico do TDPCR tem como característica a positividade para os marcadores epiteliais de citoqueratina e antígeno de membrana epitelial; para os marcadores mesenquimais desmina e vimentina; para o marcador neural enolase-neurônio específico e, algumas vezes, para a proteína S100. A superexpressão para a proteína WT1 (Wilm's Tumor Protein) tem sido demonstrado no TDPCR, caracterizando a fusão dos genes EWS/WT-1. ${ }^{11}$ Devido à origem neuroendócrina do TDPCR, ${ }^{14}$ marcadores como a cromogranina podem ser incorporados na investigação diagnóstica, ${ }^{15}$ podendo haver positividade para este anticorpo. Os anticorpos para actina e antígeno leucocitário comum resultam em reação negativa, sendo que, respectivamente, os diagnósticos diferenciais de rabdomiossarcomas e linfomas podem ser descartados com a imunoistoquímica. ${ }^{4} \mathrm{O}$ presente caso teve os resultados de imunoistoquímica compatíveis com os descritos na literatura.

Atualmente, não se dispõe de nenhuma modalidade terapêutica comprovadamente eficaz para o TDPCR. Ao contrário de outras neoplasias indiferenciadas no abdome, a ressecção cirúrgica está indicada quando possível. ${ }^{16}$ Os procedimentos cirúrgicos foram realizados em 31 dos 101 casos, sendo 14 submetidos apenas à biópsia aberta, oito pacientes tiveram ressecção subtotal e nove com ressecção ampla. ${ }^{1,3,6,7}$ Regimes de poliquimioterapia em doses elevadas, até mesmo associados ao transplante de medula óssea autólogo, têm sido empregados, entretanto, sem alterar a sobrevida dos pacientes. ${ }^{5,16}$ Alguns autores têm associado à baixa resposta à quimioterapia ao estroma fibromixóide desmoplásico. ${ }^{5,17}$ A radioterapia também mostrou ser ineficaz. ${ }^{17}$

A evolução da doença é extremamente desfavorável, havendo uma sobrevida média de 17 meses com variaçôes entre 3 e 72 meses. ${ }^{1,3,6,7} \mathrm{O}$ acometimento intraabdominal maciço tem sido a principal causa de morte dos pacientes relatados na literatura. ${ }^{1,3,5-7,16}$ 


\section{REFERÊNCIAS}

1. Gerald WL, Miller HK, Battifora H, Miettinen M, Silva EG, Rosai J. Intra-abdominal desmoplastic small roundcell tumor. Report of 19 cases of a distinctive type of highgrade polyphenotypic malignancy affecting young individuals. Am J Surg Pathol. 1991;15(6):499-513.

2. Ordóñez NG, El-Naggar AK, Ro JY, Silva EG, Mackay B. Intra-abdominal desmoplastic small cell tumor: a light microscopic, immunocytochemical, ultrastrutural, and flow cytometric study. Hum Pathol. 1993;24(8):850-65.

3. Kretschmar CS, Colbach C, Bhan I, Crombleholme TM. Desmoplastic small cell tumor: a report of three cases and a review of the literature. Am J Pediatr Hematol Oncol. 1996 Aug;18(3):293-8.

4. Frappaz D, Bouffet E, Dolbeau D, Bouvier R, Carrier C, Louis D. Desmoplastic small round cell tumors of the abdomen. Cancer. 1994 Mar 15;73(6):1753-6.

5. Bertuzzi A, Castagna L, Nozza A, Quaglioulo V, Siracusano L, Balzarotti M. High-dose chemotherapy in poor-prognosis adult small round-cell tumors: clinical and molecular results from a prospective study. J Clin Oncol. 2002 Apr 15;20(8):2181-8.

6. Gerald WL, Rosai J. Desmoplastic small cell tumor with multiphenotypic differentiation. Zentralbl Pathol. 1993 Jun;139:141-51.

7. Ordonez NG, El-Naggar AK, Ro JY, Silva EG, MacKay B. Intra-abdominal desmoplastic small cell tumor: a light microscopic, immunocytochemical, ultrastructural, and flow cytometric study. Hum Pathol. 1993;24:850-65.

8. Ordi J, Alava E, Torné A, Mellado B, Pardo-Mindam J, Iglesias X, et al. Intraabdominal desmoplastic small round cell tumor with EWS/ ERG fusion transcript. Am J Surg Pathol. 1998;22(8):1026-32.

9. Gerald WL, Ladanyi M, de Alava E, Cuatrecasas M, Hushner BH, LaQaglia MP, et al. Clinical, pathologic, and molecular spectrum of tumors associated with $\mathrm{t}(11 ; 22)$ (p13; q12): desmoplastic small round-cell tumor and its variants. J Clin Oncol. 1998;16(9):3028-36.

10. Katz RL, Quezado M, Senderowicz AM, Villalba L, Laskin WB, Tsoko MB, et al. An intra-abdominal small round cell neoplasm with features of primitive neuroectodermal and desmoplastic round cell tumor and a EWS/ FL-1 fusion transcript. Hum Pathol. 1997;28(4):502-9.

11. Ladanyi M, Gerald W. Fusion of the EWS and WT1 genes in the desmoplastic small round cell tumor. Cancer Res. 1994:54:2837-40.

12. Barnoud R, Sabourin JC, Pasquier D, Ranchere D, Bailly C, Terrier-Lacombe MJ, et al. Immunohistochemical expression of WT1 by desmoplastic small round cell tumor: a comparative study with other small round cell tumor. Am J Surg Pathol. 2000;24(6):830-6.

13. Donner L, Triche TJ, Israel MA, Seerger RC, Reynolds CP. A panel of monoclonal antibodies which discriminate neuroblastoma from Ewing's sarcoma, rhabdomiosarcoma, neuroepithelioma and hematopoietic malignancies. Prog Clin Biol Res. 1985;175:347-66.

14. Folpe AL, Hill CE, Parham DM, O'Shea PA, Weiss SW. Immunohistochemical detection of FL-1 protein expression: a study of 132 round cell tumors with emphasis on CD99positive mimics of ewing's sarcoma/ primitive neuroectodermal tumor. Am J Surg Pathol. 2000;24(12):1657-62.

15. Militello C, Cannizzaro R, Pradella P, Volpin E, Spirch S, Buonadonna $\mathrm{A}$, et al. Utilità del dosaggio della cromogranina A nella diagnosi delle neoplasie neuroendocrine. Chir Ital. 1999;51(1):45-51.

16. Bouffet E, Frappaz D, Pinkerton R, Favrot M, Philip T. Burkitt's lymphoma: a model for clinical oncology. Eur J Cancer. 1991;27:504-9.

17. Gonzalez-Crussi F, Crawford SE, Sun CJ. Intrabdominal desmoplastic small cell tumors with divergent differentiation: observations of three cases of childohood. Am J Surg. 1990;14:633-42. 